\title{
The course of neuropathy after cessation of cisplatin treatment, combined with Org 2766 or placebo
}

\author{
A.Hovestadt ${ }^{1}$, M.E.L.van der Burg ${ }^{2}$, H.B.C. Verbiest ${ }^{1}$, W. L.J.van Putten ${ }^{3}$, and C.J. Vecht ${ }^{1}$ \\ ${ }^{1}$ Department of Neurology, ${ }^{2}$ Department of Medical Oncology, and ${ }^{3}$ Department of Biostatistics, Dr. Daniel den Hoed Cancer Center, \\ P.O. Box 5201, NL-3008 AE Rotterdam, The Netherlands
}

Received January 14, 1991 / Received in revised form March 11 and May 27, 1991 / Accepted June 6, 1991

\begin{abstract}
Summary. Peripheral neuropathy is an important and disabling side-effect of cisplatin treatment. A new drug, Org 2766, has been found to prevent this neuropathy up to 1 month after treatment. A group of 18 patients with ovarian cancer, who participated in an earlier randomized study with placebo or Org 2766 , together with cisplatin and cyclophophamide, were thereafter prospectively followed up to 2 years after discontinuation of treatment to monitor the development of neurological signs and symptoms and vibration perception threshold (VPT). Exploratory, descriptive data analysis shows that between 1 and 4 months after the last cycle the average sum score for neurological signs and symptoms and VPT had deteriorated compared with 1 month after treatment. Thereafter a gradual but incomplete improvement was seen between 4-12 and 12-24 months after treatment. These changes were seen in all patients regardless of previous treatment with Org 2766 or placebo, but deterioration was less pronounced in patients previously treated with Org 2766. These results suggests that treatment with Org 2766 to prevent a cisplatin-induced neuropathy should possibly be continued up to 4 months after the last cycle of cisplatin.
\end{abstract}

Key words: Neuropathy - Cisplatin - Org 2766 - Chemotherapy - Vibration threshold

\section{Introduction}

Cisplatin has proved to be an effective anti-cancer drug, particularly in the treatment of ovarian and testicular cancer. A well-known major and dose-limiting side-effect of cisplatin is a peripheral neuropathy $[1,5,8,9,10$, $12,13,15]$. The incidence and severity of this side-effect is clearly related to the total cumulative dose of cisplatin administered. Cisplatin-induced polyneuropathy is characterized by a sensory neuropathy, due to damage of large myelinated Ia fibres, probably at the level of the

Offprint requests to: C. J. Vecht dorsal root ganglion cell [15]. The polyneuropathy is only reversible in some patients, but accurate information on the natural history after cessation of cisplating treatment is not available.

A new drug, Org 2766, an ACTH analogue, has been found in a recent study to be able to prevent the neuropathy when given concomitantly with cisplatin $[4,6]$. A group of 18 patients who participated in that study have been followed to monitor the course of neuropathic signs and symptoms after discontinuation of treatment with cisplatin and Org 2766. Our observations are reported here.

\section{Materials and methods}

All patients participated in a multi-centre double-blind, placebocontrolled randomized trial in which treatment with cisplatin was combined with two different doses of Org 2766 or placebo [6]. Women eligible for this study had a histologically verified epithelial ovarian carcinoma, FIGO stage III or IV. Exclusion criteria were: age over 70 years, previous chemotherapy, established clinical or subclinical neuropathy, diabetes mellitus, alcohol abuse, brain involvement or leptomeningeal disease, or inadequate bone marrow, liver or renal function. Patients receiving vitamin B supplements or other vitamin diets were also excluded. Performance status according to the World Health Organization scale had to be 2 or better, that is less than $50 \%$ of normal day-time hours spent in bed.

Chemotherapy consisted of cyclophosphamide $\left(750 \mathrm{mg} / \mathrm{m}^{2}\right)$ and cisplatin $\left(75 \mathrm{mg} / \mathrm{m}^{2}\right)$ every 3 weeks, up to a maximum of nine cycles if possible.

Org 2766 was injected subcutaneously before the start of cisplating administration and $24 \mathrm{~h}$ later. It was administered in a low $\left(0.25 \mathrm{mg} / \mathrm{m}^{2}\right)$ or high $\left(1 \mathrm{mg} / \mathrm{m}^{2}\right)$ dose. An equal amount of mannitol served as placebo. The results during treatment until after the sixth cycle of cisplatin in this multic-centre study have been reported [6]. Thereafter, patients from our hospital were followed and examined in the neurology clinic for neuropathic signs and symptoms and vibration threshold. Seven of 25 participating patients from our institution were not eligible for further follow-up because of progressive disease or death before the sixth cycle. In the remaining 18 patients examinations were performed within 1 month after the last cycle, between 1 and 4 months, between 4 and 12 months and between 12 and 24 months after the last cycle of cisplatin. 
Table 1. Correlation coefficients between neurological signs and symptoms and vibration perception threshold (VPT). Correlation coefficients $(r)$ based on a total of 75 observations in 18 patients

\begin{tabular}{lllll}
\hline & Log VPT & Sum I & Sum II & Sum III \\
\hline Log VPT & 1.00 & & & \\
Sum I & 0.75 & 1.00 & & \\
$\quad$ II & 0.73 & 0.67 & 1.00 & \\
III & 0.81 & 0.88 & 0.94 & 1.00 \\
\hline
\end{tabular}

Table 2. Number of observations in each time period. $n$, Number of patients in each group

\begin{tabular}{|c|c|c|c|c|c|}
\hline & $\begin{array}{l}\text { Before } \\
\text { treat- } \\
\text { ment } \\
(n)\end{array}$ & $\begin{array}{l}1 \text { month } \\
\text { after } \\
\text { treat- } \\
\text { ment } \\
(n)\end{array}$ & $\begin{array}{l}1-4 \\
\text { months } \\
\text { after } \\
\text { treat } \\
\text { ment } \\
(n)\end{array}$ & $\begin{array}{l}4-12 \\
\text { months } \\
\text { after } \\
\text { treat } \\
\text { ment } \\
(n)\end{array}$ & $\begin{array}{l}12-24 \\
\text { months } \\
\text { after } \\
\text { treat } \\
\text { ment } \\
(n)\end{array}$ \\
\hline All patients & 18 & 12 & 13 & 16 & 9 \\
\hline Placebo & 7 & 6 & 5 & 6 & 4 \\
\hline Org low & 5 & 4 & 3 & 4 & 2 \\
\hline Org high & 6 & 2 & 5 & 6 & 3 \\
\hline
\end{tabular}

All patients had to answer a questionnaire with regard to the presence of absence of paraesthesias, numbness, loss of strength, loss of dexterity, unstaediness of gait, pain and Lhermitte's sign. Various tests, including sense of pain, fine touch, vibration sense, Romberg's sign and straight line walking heel-to-toe, patellar and Achilles tendon reflexes were performed and scored as abnormal or normal.

Separate sum scores were calculated for symptoms (sum score $\mathrm{I}$; minimum $\mathrm{O}$, maximum 6), signs (sum score $\mathrm{II}$; minimum $\mathrm{O}$, maximum 10) and sum score III, being the total of sum scores I and II.
In all patients the threshold of vibration perception (VPT) was measured by Vibrameter Type III (Somedic, Stockholm, Sweden) on the second metacarpal bone of the left hand, expressed in micromillimetres [7].

No a priori hypothesis about the further course of neuropathy after cessation of treatment was specified. Therefore the analysis was primarily exploratory, aiming at a description of the level of neuropathy as a function of time after treatment. This was achieved by calculation of the mean values of VPT and sum scores in four periods after treatment. Formal tests for significance were not performed because of the limited number of patients and the exploratory character of the study.

\section{Results}

The average number of cycles was 6.9 (SD 1.3), with 6.4 (SD 1.3) in the placebo group ( $n=7), 7.0$ (SD 1.4) in the low-dose Org group $(n=5)$ and 7.3 (SD 1.4) cycles in the high-dose Org group $(n=6)$. This corresponds to a cumulative dose of cisplatin of $518 \mathrm{mg} / \mathrm{m}^{2}$ for the whole group and $480 \mathrm{mg} / \mathrm{m}^{2}$ for placebo, $550 \mathrm{mg} / \mathrm{m}^{2}$ for lowdose, and $570 \mathrm{mg} / \mathrm{m}^{2}$ cisplatin for high-dose Org.

Correlation coefficients between vibration threshold and sum scores of signs and symptoms based on all available multiple observations of the patients were 0.67 or higher (Table 1).

The total number of patients at each point in time is given in Table 2, showing that between 9 and 16 single observations were recorded in each time period. As all patients had participated in a randomized double-blinded trial with placebo or low or high-dose Org 2766, the tables also include data on each of these subgroups. The main emphasis, however, will be on the combined results with or without Org 2766 after discontinuation of treatment with cisplatin and cyclophosphamide.

Table 3 lists the sum scores of neurological signs and symptoms and average of VPT over time. Between 1 and
Table 3. Course of sum scores of neurological signs and symptoms and VPT over time. Sum I indicates the average sum score (SD) of neurological symptoms, sum II of neurological signs and sum III the total of sum scores I and II. The VPT values represent the geometrical mean (SD)

\begin{tabular}{|c|c|c|c|c|c|}
\hline & $\begin{array}{l}\text { Before } \\
\text { treatment } \\
(n=18)\end{array}$ & $\begin{array}{l}1 \text { month } \\
\text { after } \\
\text { treatment } \\
(n=12)\end{array}$ & $\begin{array}{l}1-4 \\
\text { months } \\
\text { after } \\
\text { treatment } \\
(n=13)\end{array}$ & $\begin{array}{l}4-12 \\
\text { months } \\
\text { after } \\
\text { treatment } \\
(n=16)\end{array}$ & $\begin{array}{l}12-24 \\
\text { months } \\
\text { after } \\
\text { treatment } \\
(n=9)\end{array}$ \\
\hline Sum I in all patients & 0 & $2.4(2.3)$ & $3.3(1.9)$ & $2.5(1.8)$ & $1.3(1.6)$ \\
\hline Placebo & - & 2.5 & 3.5 & 3.3 & 2.3 \\
\hline Org low & - & 3.5 & 4.7 & 2.3 & 0.5 \\
\hline Org high & - & 0.0 & 2.2 & 2.0 & 0.7 \\
\hline Sum II in all patients & 0 & $2.8(2.9)$ & $4.0(3.5)$ & $2.2(2.1)$ & $1.1(1.7)$ \\
\hline Placebo & - & 3.8 & 3.8 & 2.5 & 2.3 \\
\hline Org low & - & 2.8 & 6.3 & 2.5 & 0.0 \\
\hline Org high & - & 0.0 & 2.8 & 1.6 & 0.3 \\
\hline Sum III in all patients & 0 & $5.3(4.7)$ & $7.2(4.8)$ & $4.6(3.6)$ & $2.0(2.9)$ \\
\hline Placebo & - & 6.3 & 7.2 & 5.7 & 4.0 \\
\hline Org low & - & 6.3 & 11.0 & 4.5 & 0.5 \\
\hline Org high & - & 0.0 & 5.0 & 3.5 & 1.0 \\
\hline VPT in all patients & $0.4(0.3)$ & $2.8(2.9)$ & $5.9(7.0)$ & $3.2(4.4)$ & $2.9(1.1)$ \\
\hline Placebo & 0.6 & 3.7 & 8.1 & 4.8 & 2.9 \\
\hline Org low & 0.5 & 2.9 & 14.6 & 3.6 & 0.6 \\
\hline Org high & 0.5 & 1.1 & 2.5 & 2.0 & 0.8 \\
\hline
\end{tabular}




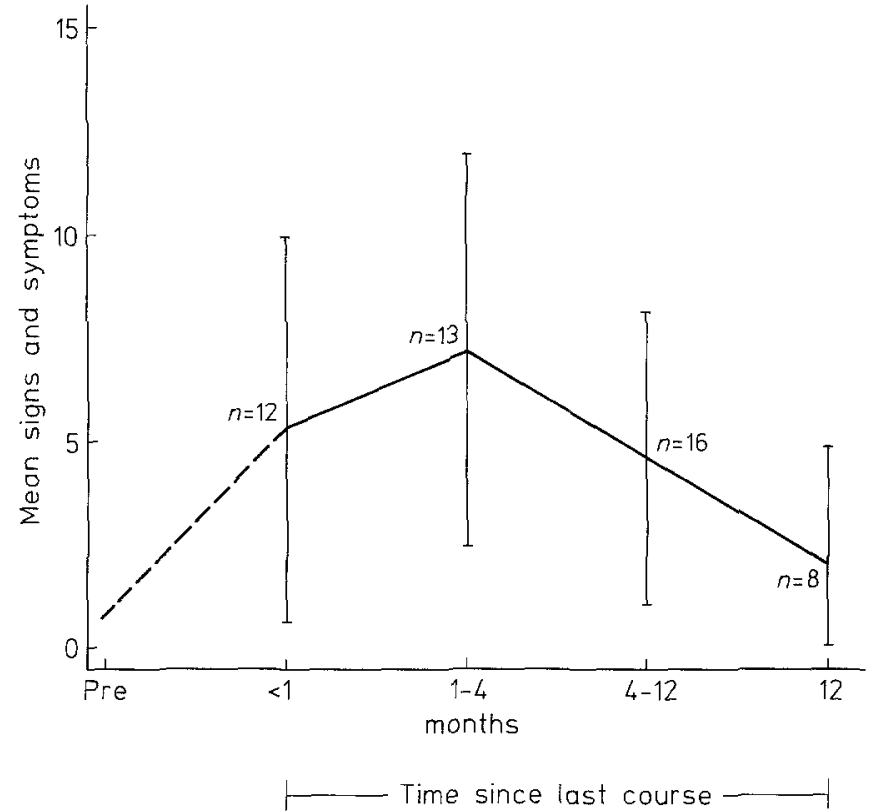

Fig.1. Average sum score III of neurological signs, symptoms and standard deviation for all patients

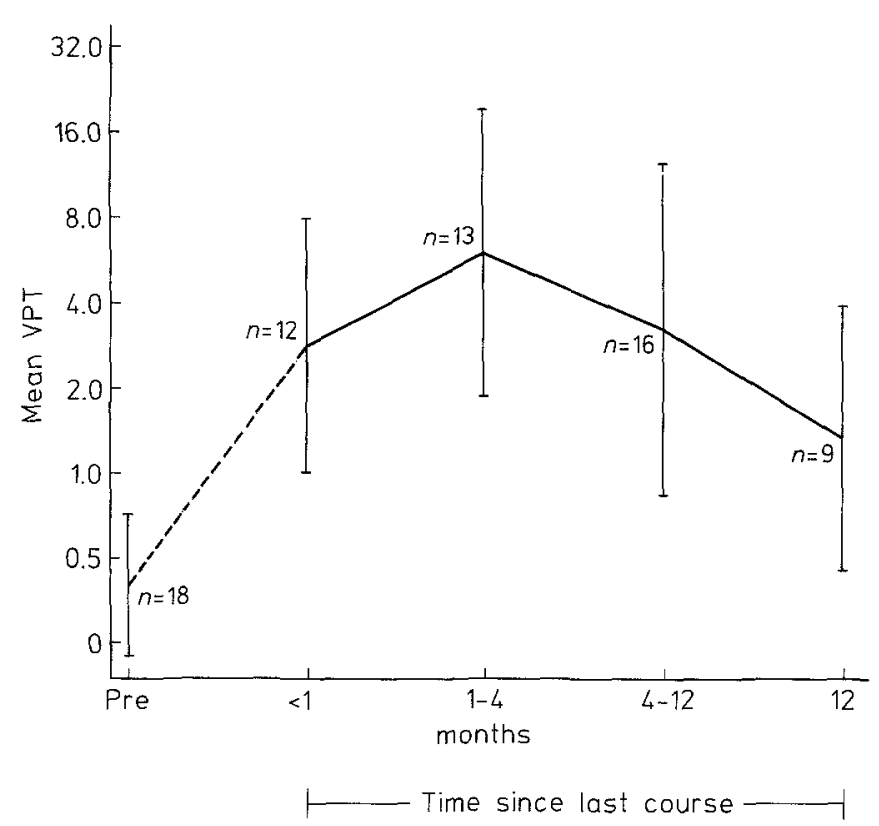

Fig. 2. Average log vibration perception threshold and standard deviation for all patients

4 months after the last cycle, neurological signs and symptoms and VPT further deteriorated in all patients compared with within 1 month after discontinuation of treatment. Between 4-12 months and 12-24 months after the last cycle, the neurological sum scores and VPT showed a gradual improvement, but values did not normalize. The time-course for the sum score of neurological signs and average log VPT is graphically shown in Figs. 1 and 2. To indicate the variation between individual patients, bars in these figures represent standard deviations and not standard errors of the mean.
Sixteen patients had multiple observations in the first half-year after treatment. Sum score III deteriorated in this period in 6 patients and remained about the same in 10 patients. The VPT deteriorated in 9 patients and remained on the same level in the other 7 patients.

As in the multicentre study we can also observe here that patients receiving high-dose Org had better scores at 1 month after the last cycle than those treated with placebo or low-dose Org. Thereafter patients in all subgroups deteriorated. Patients who had received highdose Org showed less deterioration between 1 and 4 months than the other two subgroups, although patients with low-dose Org did worse than patients who had received placebo, but numbers per subgroup were too small for statistical comparison (Table 3). Patients with high-dose Org had an average sum score for signs and symptoms of 0 at 1 month after treatment, 5.0 at $1-4$ months, 3.5 at 4-12 and 1.0 at 12-24 months after discontinuation of treatment with cisplatin. To indicate the variation over time for individual patients, Fig. 3 shows the plots of VPT of patients previously treated with placebo, low- or high-dose Org.

\section{Discussion}

These results indicate that signs and symptoms of cisplatin-induced neuropathy progressed after discontinuation of cisplatin for a period of about 4 months, followed by a spontaneous amelioration during the following 12-24 months, but that they did not normalize. This pattern is evident for the VPT measurements and for the sum scores of signs and symptoms. The measurement of VPT compared with nerve conduction velocities has the advantage that it can be recorded quantitavely and accurately without causing discomfort to the patient $[3,7$, 13]. It is also closely related to the severity of the clinical neuropathy as shown by high correlations with sum scores for signs and symptoms.

We observed that patients previously treated with Org 2766 also deteriorated between 1 and 4 months after the last cycle. However, the numbers of observations in each subgroup previously treated with placebo, high- or low-dose Org 2766 are too small to allow for statistical analysis and the differences between these groups could still be explained by chance variation. It is therefore possible that the differences between the subgroups only reflect the maximum damage incurred by cisplatin to sensory nerve function, rather than the effect of Org 2766 .

In a study of 30 patients treated with cisplatin, vinblastine and bleomycin for germ cell cancer and examined between 49 and 106 months after cessation of treatment [9], the majority of patients still had abnormal values for VPT and nerve conduction velocities [9]. In two consecutive chemotherapy trials, neuropathy in any grade of toxicity developed in $47 \%$ of patients treated with a cisplatin-containing regimen. In patients who survived for more than 5 years, the incidence of cisplatin neuropathy was $61 \%$. In a preliminary report, deterioration of neuropathic signs and symptoms has been reported in 

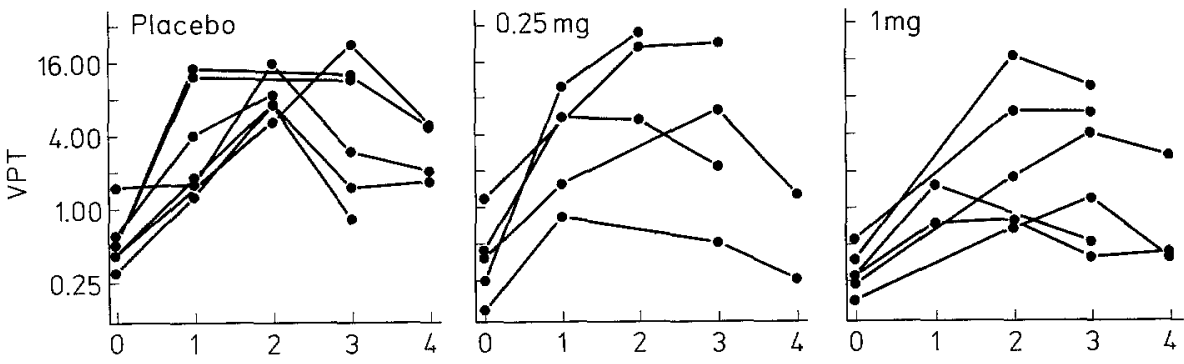

Fig. 3. Changes in vibration perception threshold over time in individual patients previously treated with placebo, low-dose $(0.25)$ or high-dose $(1 \mathrm{mg})$ Org. On the $X$-axis the time-course is indicated by: 0 , pretreatment; 1 , within 1 month after last cycie; 2 , between 1 and 4 months after last cycle; 3 , between 4 and 12 months after last cycle; 4 , between 12 and 24 months after last cycle one-third of patients after cisplatin treatment followed by incomplete recovery [14].

Mollman et al. [11] described three cases of delayed peripheral neuropathy developing signs and symptoms 3-8 weeks after completion of cisplating therapy, with a recovery in two patients after 8 and 27 months.

In experimental animal studies, sensory nerve conduction velocities improved considerably the first 15 weeks after discontinuation of cisplain [4]. However, these studies were performed in young growing rats.

Morphological studies have demonstrated that changes caused by cisplatin consist primarily of axonal damage with secondary demyelination [15]. With Org 2766 it has been found that it is possible to prevent the neurotoxic effects of cisplatin $[4,6]$. The mechanism of this effect is however, unclear, but two hypotheses might be offered: (1.) protection, in which Org 2766 might prevent the directly toxic effect of cisplatin on the axon; (2.) repair, in which Org 2766 enhances the repair capacity of the axon [2].

The worsening of the polyneuropathy after discontinuation of cisplatin argues against the first hypothesis, as one would no expect progression if Org 2766 is a protective drug. However, if Org 2766 enhances the repair capacities of the sensory neuron or axon, one might expect a progression of the polyneuropathy after simultaneous discontinuation of cisplatin and Org 2766. Our data, therefore, would support the repair mechanism hypothesis [2].

As we established in a previous study that high-dose Org 2766 could prevent the neuropathy when given concomitantly with cisplatin [6] and we now found that after cessation of treatment a deterioration of sensory function nevertheless developed between 1 and 4 months later, these observations would suggest that administering Org 2766 should be continued until the end of this period.

In conclusion, our results show that deterioration of clinical signs and VPT in cisplatin-induced neuropathy continues during the first 4 months after cessation of cisplatin treatment. Subsequently, a gradual but incomplete improvement is seen up to 2 years after treatment. The beneficial effect of the ACTH analogue Org 2766 seems to be based on enhancing repair mechanisms rather than on preventing damaging effects of cisplatin on nerve fibres or dorsal root ganglion cells.

Acknowledgement. We acknowledge the help of Janet van Vliet with data management and the manuscript.

\section{References}

1. Daugaard GK, Petrera J, Trojaborg W (1987) Electrophysiological study of the peripheral and central neurotoxic effect of cis-platin. Acta Neurol Scand 76:85-93

2. Edwards PM, Van der Zee CE, Verhaagen J, Schotman P, Jennekens FGI, Gispen WH (1984) Evidence that the neurotrophic actions of alpha-MSH may derive from its ability to mimic the actions of a peptide formed in degenerating nerve stumps. J Neurol Sci $64: 333-340$

3. Elderson A, Gerritsen van der Hoop R, Haanstra W, Neyt JP, Gispen WH, Jennekens FGI (1989) Vibration perception and thermoperception as quantitative measurements in the monitoring of cisplatin-induced neuropathy. J Neurol Sci 93:167174

4. Gerritsen van der Hoop R, Koning P de, Boven E, Neijt JP, Jennekens FGI, Gispen WH (1988) Efficacy of the neuropeptide ORG. 2766 in the prevention and treatment of Cisplatininduced neurotoxicity in rats. Eur J Cancer Clin Oncol 4:637642

5. Gerritsen van der Hoop R, Burg MEL van der, Ten Bokkel Huinink WW, Houwelingen JC van, Neyt JP (1990) Incidence of neuropathy in 395 patients with ovarian cancer treated with or without cisplatin. Cancer 66:1697-1702

6. Gerritsen van der Hoop R, Vecht CJ, Burg MEL van der, Elderson A, Boogerd W, Heimans JJ, Vries EP, Houwelingen JC van, Jennekens FGI, Gispen WH, Neijt JP (1990) Prevention of cisplatin neurotoxicity with an ACTH (4-9) analogue in patients with ovarian cancer. N Engl J Med 322:89-94

7. Goldberg JM, Lindblom U (1979) Standardised method of determining vibratory perception threshold for diagnosis and screening in neurological investigation. J Neurol Neurosurg Psychiatry 42:793-803

8. Grunberg SM, Sonka S, Stevenson LL, Muggia FM (1989) Progressive paresthesias after cessation of therapy with very high-dose cisplatin. Cancer Chemother Pharmacol 25:62-64

9. Hansen SW, Helweg-Larsen S, Trojaborg W (1989) Long-term neurotoxicity in patients treated with cisplatin, vinblastine, and bleomycin for metastatic germ cell cancer. J Clin Oncol $7: 1457-1461$

10. Legha SS, Dimery IW (1985) High-dose cisplatin administration without hypertonic saline: observation of disabling neurotoxicity. J Clin Oncol 3:1373-1378

11. Mollman JE, Hogan M, Glover DJ, et al. (1988) Unusual presentation of cis-platinum neuropathy. Neurology 38:488-490

12. Ongerboer de Visser BW, Tiessens G (1985) Polyneuropathy induced by cisplatin. Prog Exp Tumor Res 29:190-196

13. Roelofs RI, Hrushesky W, Rogin J, Rosenberg L (1984) Peripheral sensory neuropathy and cisplatin chemotherapy. Neurolgoy $34: 934-938$

14. Siegal T, Haim N (1990) Cisplatin-induced peripheral neuropathy. Frequent off-therapy deterioration, demyelinating syndromes, and muscle cramps. Cancer 66:1117-1123

15. Thompson SW, Davis LE, Kornfeld M, Hilgers RD, Standefer JC (1984) Cisplatin neuropathy, clinical, electrophysiologic, morphologic, and toxicologic studies. Cancer 54:1269-1275 